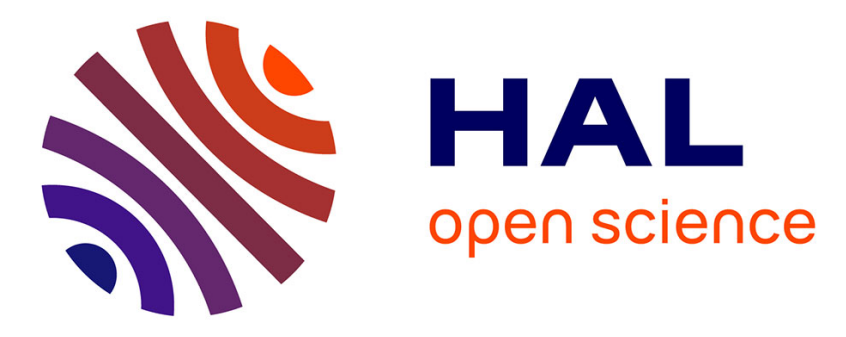

\title{
High Temperature Internal Friction in NiAl Single Crystals
}

\author{
M. Weller, M. Hirscher, E. Schweizer, H. Kronmüller
}

\section{To cite this version:}

M. Weller, M. Hirscher, E. Schweizer, H. Kronmüller. High Temperature Internal Friction in NiAl Single Crystals. Journal de Physique IV Proceedings, 1996, 06 (C8), pp.C8-231-C8-234. 10.1051/jp4:1996849 . jpa-00254657

\section{HAL Id: jpa-00254657 https://hal.science/jpa-00254657}

Submitted on 1 Jan 1996

HAL is a multi-disciplinary open access archive for the deposit and dissemination of scientific research documents, whether they are published or not. The documents may come from teaching and research institutions in France or abroad, or from public or private research centers.
L'archive ouverte pluridisciplinaire HAL, est destinée au dépôt et à la diffusion de documents scientifiques de niveau recherche, publiés ou non, émanant des établissements d'enseignement et de recherche français ou étrangers, des laboratoires publics ou privés. 


\title{
High Temperature Internal Friction in NiAl Single Crystals
}

\author{
M. Weller, M. Hirscher*, E. Schweizer* and H. Kronmüller* \\ Max-Planck-Institut für Metallforschung, Institut für Werkstoffwissenschaft, Seestrasse 92, \\ 70174 Stuttgart, Germany \\ * Institut für Physik, Heisenbergstrasse 1, 70569 Stuttgart, Germany
}

\begin{abstract}
The internal friction of high-purity NiAl single crystals was investigated utilizing a low-frequency subresonance torsion apparatus. Above $1000 \mathrm{~K}$ the damping increases strongly up to $Q^{-1}=0.3$ at $1400 \mathrm{~K}$. The activation enthalpy of this viscoelastic relaxation depends on the composition and shows the highest value $(2.8 \mathrm{eV})$ for stoichiometric NiAl. The results are discussed in terms of diffusion-controlled climb of dislocations by vacancies.
\end{abstract}

\section{INTRODUCTION}

The B2-ordered intermetallic compound $\mathrm{NiAl}$ exhibits a variety of interesting physical properties such as metal-like electrical and thermal conductivity and low density. Its high stiffness (elastic modulus), good oxidation resistance and high melting point $(\approx 1900 \mathrm{~K})$ anticipates application as structure material for high temperature applications. The mechanical properties of materials at high temperatures are largely determined by the creep properties. The creep behaviour of a material is closely related to self diffusion and, therefore, to the presence and formation of point defects (e.g. vacancies), as pointed out in recent reviews on $\mathrm{NiAl}[1,2]$. Mechanical loss (internal friction) experiments give another access for the study of the high temperature strength of materials. In a wide range of materials the internal friction exhibits a rapid increase at high temperatures [3,4]. Recent experiments on NiAl single crystals with stoichiometric composition [5] showed that the activation enthalpy of the thermally activated .high temperature background $\mathrm{H}=(2.6 \pm 0.2) \mathrm{eV}$ is close to that for self diffusion of $\mathrm{Ni}$ in $\mathrm{NiAl}(\mathrm{H} \approx 3 \mathrm{eV})$. This points to a viscoelastic deformation behaviour at high temperatures by contribution of atomic defects, comparable to diffusional creep. In the present paper we report on mechanical loss measurements on NiAl with various compositions near the stoichiometry, to obtain more insight into the correlation between defect/ diffuision properties and the high temperature damping.

\section{THEORETICAL BACKGROUND}

In many metals, alloys and ceramics a large increase of the internal friction occurs at high temperatures. This damping is found to be independent of strain amplitude and rises with temperature without indication of a relaxation peak. Such a behaviour is characteristic for either anelastic or viscoelastic relaxation [4]. One method to distinguish between both are quasistatic experiments, since anelastic relaxation is expected to be completely recoverable in contrast to viscoelastic relaxation. However, such experiments lead to technical difficulties because of the high temperatures involved (for $\mathrm{NiAl}$ up to $1400 \mathrm{~K}$ ). Another experimental approach are dynamical low frequency experiments which are now possible for the frequency range of about $10^{-4} \mathrm{~Hz}$ to $10 \mathrm{~Hz}$ [6]. These experiments require knowledge of the (complex) dynamic response functions $M_{1}(\omega)$ and $M_{2}(\omega)$ for viscoelastic relaxation. Since these are not given in standard textbooks $[4,7]$, their calculation will be presented briefly in the following.

Viscoelastic behaviour of a solid can be represented by a rheological model consisting of spring with modulus $M$ in series with a dashpot with viscosity $\eta=\tau \mathbf{M}(\tau=$ relaxation time $)$. This is the well-known Maxwell-model which can be described by the following differential equation [4]. 


$$
\tau \dot{\sigma}+\sigma=\tau \mathrm{M} \dot{\varepsilon}
$$

( $\sigma=$ stress, $\varepsilon=$ strain etc.). Equation (1) describes steady viscous creep which does not recover upon removal of stress. For dynamic experiments periodic stress and strain can be expressed by the complex notations [4] $\varepsilon=\varepsilon_{0} \mathrm{e}^{\mathrm{i} \omega t}$ and $\sigma=\sigma_{0} \mathrm{e}^{\mathrm{i}(\omega t+\phi)}=\left[\mathrm{M}_{1}(\omega)+\mathrm{i} \mathrm{M}_{2}(\omega)\right] \varepsilon_{\mathrm{o}} \mathrm{e}^{\mathrm{i} \omega t}$, where $\phi$ is the loss angle. Insertion into eq. (1) and separating of real and imaginary part gives the loss tangent, i.e. the internal friction $Q^{-1}$

$$
Q^{-1}=\tan \phi=\frac{M_{2}(\omega)}{M_{1}(\omega)}=\frac{1}{\omega \tau} \text {. }
$$

An analogous equation can be derived for the modulus [8]: Since high temperature viscoelastic behaviour is determined by thermally activated processes, an Arrhenius equation holds for the relaxation time $\tau$

$$
\tau^{-1}=\tau_{\infty}^{-1} \exp (-\mathrm{H} / \mathrm{kT})
$$

Combination of equations (2) and (3) gives for the temperature dependence, $Q^{-1}(T)$, of viscoelastic relaxation

$$
\mathrm{Q}^{-1}=\frac{\mathrm{A}}{\omega \exp (\mathrm{H} / \mathrm{kT})},
$$

with $\mathrm{A}=\tau_{\infty}{ }^{-1}$. Equation (5) is equal to that given by Schöck et al. (eq. 6 in [3]). However, their equation was derived by assuming a relaxation model with dislocation motion in a viscous way which, in contrast to eq. (1) is described by a Voigt model (parallel dashpot plus spring) $\sigma=a \varepsilon+b \dot{\varepsilon}$ [4]). Furthermore, the internal friction was taken as the imaginary part of the strain, which is only applicable for small damping. A distribution of relaxation times can be introduced empirically, as proposed by Schöck et al [3], by modifying equation (5) as

$$
\mathrm{Q}^{-1}=\frac{\mathrm{A}}{\omega^{\mathrm{n}} \exp (\mathrm{H} / \mathrm{kT})^{\mathrm{n}}} \text {. }
$$

The quantity $1 / \mathrm{n}$ characterizes the width of the distribution. Ideal viscoelasticity corresponds to $n=1$. The (true) activation enthalpy $\mathrm{H}$ can be determined from the frequency shift of the background for a constant value of $\mathrm{Q}^{-1}$ independent of if there is a distribution of relaxation times or not. A convenient way of data evaluation follows from eq. (5)

$$
\ln \mathrm{Q}^{-1}+\mathrm{n} \ln \omega=\ln \mathrm{A}-\mathrm{nH} / \mathrm{kT} \text {. }
$$

\section{EXPERIMENTAL RESULTS}

The NiAl alloys with various $\mathrm{Ni} / \mathrm{Al}$ contents were prepared by induction melting of 99,998 pure Ni and 99,999\% pure $\mathrm{Al}$ under Ar atmosphere and casting into $\mathrm{Cu}$ crucibles. Single crystals were prepared by crucible free inductive zone melting under Ar atmosphere. The orientation of the crystals was near the $<100>$ direction. The composition was determined by chemical analysis (see Table 1). The temperature dependence of the internal friction, $Q^{-1}(T)$, was determined in a subresonance torsion apparatus (for details see [8]) for various frequencies between $10^{-2} \mathrm{~Hz}$ and $10 \mathrm{~Hz}$.

Fig. 1 shows mechanical loss measurements of a stoichiometric $\mathrm{NiAl}$ single crystal for frequencies in the range of $0.01 \mathrm{~Hz}$ to $10 \mathrm{~Hz}$. The rise of the damping temperature curves, $\mathrm{Q}_{\mathrm{ht}}(\mathrm{T})$, strongly increases with decreasing measuring frequency, as expected for viscoelastic damping. The influence of the alloy composition on $Q^{-1} h(T)$ for a common measuring frequency $(f=0.1 \mathrm{~Hz})$ is demonstrated in Fig. 2 for various $\mathrm{Al}$ contents between 47 and 51 at $\%$. $\mathrm{Q}^{-1}{ }_{\mathrm{h}}(\mathrm{T})$ increases systematically in the sequence $47 \rightarrow 49 \rightarrow$ 50 at $\% \mathrm{Al}$ followed by a decrease for 51 at. \% Al. The temperature dependence of $\mathrm{Q}^{-1} \mathrm{ht}(\mathrm{T})$ for the various frequencies was evaluated for all specimens by applying equation ( $5 \mathrm{a}$ ) In this representation the $Q^{-1} \mathrm{ht}(\mathrm{T})$ data for various frequencies should fall in a common line with an appropriate value of $n$. This could be verified for all specimens (Table 1). An example is given in Fig.3. Using this value of $\mathrm{n}$ the (true) activation enthalpy can be obtained from the slope of the line. 


\begin{tabular}{|c|c|c|}
\hline WU⿴囗十 $\%$ & 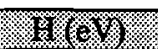 & $3 x$ \\
\hline $47 \pm 0.3$ & $2.20 \pm 0.2$ & 0.6 \\
\hline $49 \pm 0.3$ & $2.52 \pm 0.2$ & 0.55 \\
\hline $50 \pm 0.3$ & $2.81 \pm 0.2$ & 0.55 \\
\hline $51 \pm 0.3$ & $2.48 \pm 0.2$ & 0.38 \\
\hline
\end{tabular}

Table 1: Values of

$\mathrm{H}$ and $\mathrm{n}$ for

various specimens.

The activation enthalpy has a maximum value for stoichiometric composition and decreases for both $\mathrm{Ni}$ and $\mathrm{Al}$ deficiency. The spectrum parameter decreases continuously with increasing $\mathrm{Al}$ content. The variation of the activation enthalpy with $\mathrm{Al}$ contents is represented in Fig. 4.

\section{DISCUSSION AND CONCLUSIONS}

The experimental results indicate that the high temperature damping, $\mathrm{Q}^{-1}{ }_{\mathrm{ht}}(\mathrm{T})$, in NiAl is determined by viscoelastic relaxation. The activation enthalpy $\mathrm{H}$ controlling $\mathrm{Q}^{-1}{ }_{\mathrm{ht}}(\mathrm{T})$, has its highest value of $\mathrm{H}=2.8 \mathrm{eV}$ for stoichiometric $\mathrm{Ni}_{50} \mathrm{Al}_{50}$, This value is close to that for tracer diffusion of $\mathrm{Ni}$ in $\mathrm{NiAl}(3.2 \mathrm{eV})$. The decrease of $\mathbf{H}$ with increasing deviation from stoichiometry is close to that reported for self diffusion experiments (see e.g. [1,2]). From this analogous behaviour we conclude that the high temperature background in $\mathrm{NiAl}$ single crystals is determined by diffusion controlled movement of dislocations, i.e. climb of dislocations via point defects (vacancies). This interpretation agrees with results from creep experiments which indicate that high temperature creep in NiAl is climb controlled, i.e. that dislocation glide occurs faster than dislocation climb. Experiments on deformed NiAl [9] indicate that dislocation glide via thermally activated generation of kink pairs occurs with lower activation enthalpy than that for dislocation climb.

\section{References}

[1] Miracle D.B., Acta metall. mater. 41 (1993) 649-684.

[2] Noebe R.D., Bowman R.R., and Nathal M.V., Int. Mater. Reviews 38 (1993) 193-232.

[3] Schoeck G., Bisogni E., Shyne E., Acta Metall. 12 (1964) 1466 - 1468.

[4] Nowick A.S., Berry B.S., Anelastic Relaxation in Crystalline Solids, (Academic Press, N.Y, 1972).

[5] Hirscher M., Schweizer E., Weller M. and Kronmüller H.,"Internal Friction in NiAl Single Crystals", Phil.Mag.Lett., in press

[6] Weller M., J. de Physique IV, 5, C7 (1995) 199-204.

[7] De Batist, R., Internal Friction of Structural Defects in Crystalline Solids (North-Holland Publ. Co., Amsterdam, 1972).

[8] Weller M., Haneczok $G$, to be published.

[9] Schaible, D., Hirscher, M., and Kronmüller, H., to be published.

\section{Acknowledgements}

The authors are indebted to Mr. R. Henes and Mr. W. Maisch for the specimen preparation. Furthermore, we are very grateful to the Deutsche Forschungsgemeinschaft for financial support. 

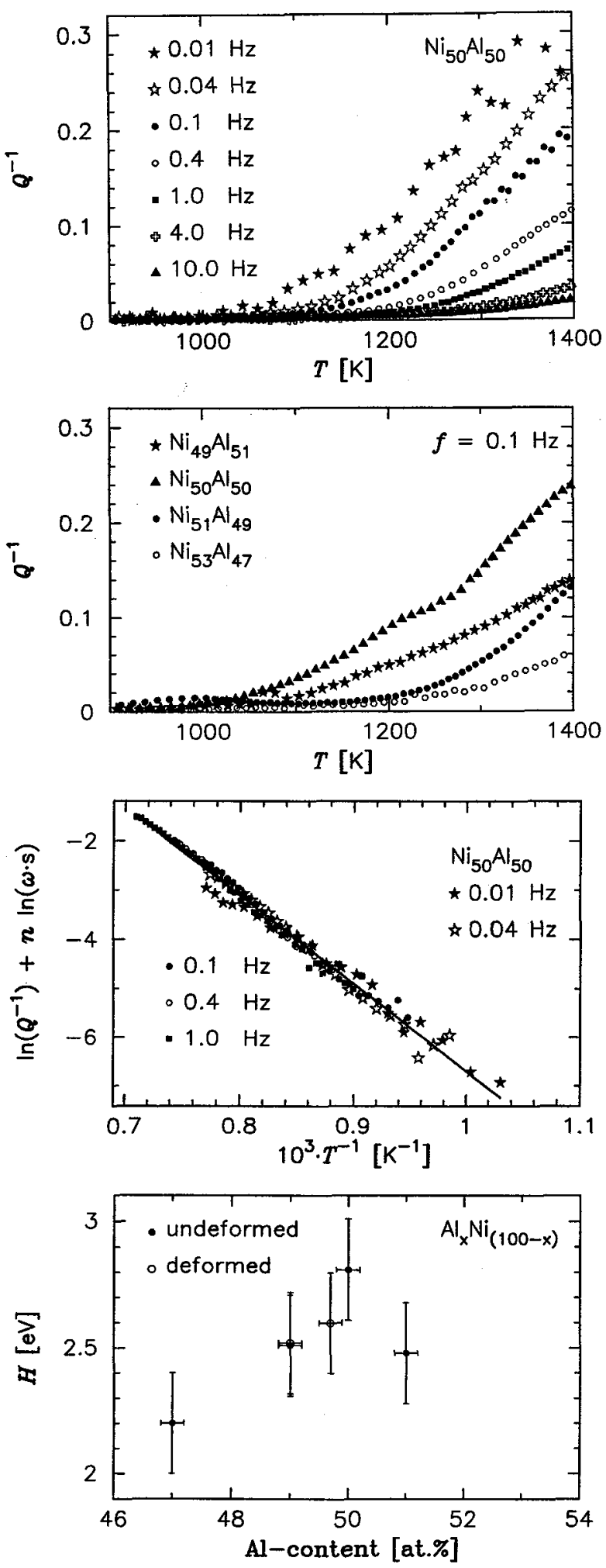

Fig. 1: Internal friction measurements of $\mathrm{Ni}_{50} \mathrm{Al}_{50}$ at different frequencies.

Fig. 2: Internal friction of NiAl single crystals with various composition for $\mathrm{f}=0.1 \mathrm{~Hz}$.

Fig. 3: Plot of $\left(\ln Q^{-1}+n \ln \omega\right)$ versus $1 / \mathrm{T}$ of $\mathrm{Ni}_{50} \mathrm{Al}_{50}$

Fig. 4: Variation of the activation enthalpy with Al-contents. 